\title{
The chronotopes of authenticity
}

\section{Designing the Tujia heritage in China}

\author{
Xuan Wang \& Sjaak Kroon \\ University of Cardiff, United Kingdom / University of Tilburg, The Netherlands
}

This paper examines the ways in which the ethnic minority group the Tujia in Enshi, China, engages with heritage tourism, as a complex project of designing authenticity. Authenticity is taken as part of the chronotopic phenomena of identity making: the complex interplay of multiple, nonrandom timespace frames of discourses and semiotic performances which condition and offer new potentials to the meanings of authenticity. We show ethnographically the chronotopic nature of the local production of "authentic" heritage for tourism in Enshi. This leads to a historical grounding of the Tujia in China's nationbuilding and state politics of multiculturalism, which uncovers the anxiety of inauthenticity experienced by the Tujia in Enshi with their own minority status and cultural heritage, as well as their strategic chronotopic incorporation of both "authentic" and "inauthentic" aspects of local identity practices into a new order of authenticity afforded by heritage tourism as a form of new economy. Through such practices, we argue, the Tujia in Enshi chronotopically shift away from the periphery towards a new and reconfigured center of meaning-making, although this reappropriation of authenticity still must be understood within the "cunning of recognition" scheme, i.e. within the constraints of late modernity.

Keywords: authenticity; the Tujia; China; heritage; chronotope; heritage tourism

\section{Introduction}

In this paper we focus on the ethnic minority group of the Tujia in Enshi, China, a community with its minority status "manipulated" locally and "given" by the state (Brown, 2002), as an instance of geopolitical and sociocultural periphery. We examine the ways in which this community in the periphery, described historically as "the highlanders of Central China" (Ch'en, 1992), engages with heritage tourism as a complex project of designing authenticity. We take authenticity as part of the chronotopic phenomena of identity making: becoming authentic involves the complex shaping and interplay of multiple, nonrandom timespace 
frames for discourses and semiotic performances, which condition as well as offer new potentials to the meanings of authenticity. We observe how the Tujia in Enshi are confronted with the issue of authenticity as effects of political and economic imperatives during China's modernization and globalization, notably in China's newly emerged agenda of heritage tourism.

Taking the perspective of the sociolinguistics of peripheral globalization, our study finds the Bahktinian notion of chronotope a useful heuristic of meaningmaking (in combination with notions such as indexicality, scale, and complexity). Chronotope not only offers an empirical tool for observing the timespace configurations of semiotic and discursive behaviors for authenticity in Enshi's heritage tourism, it also enables us to adopt an ethnographically contextualized and holistic interpretation of authenticity - especially in view of the "inauthenticity" perceived and experienced in the case of the Tujia in Enshi - understood here as multi-scaled, synchronically displayed and historically invoked processes, that are chronotopically reorganized and reordered by the peripheral group in a bigger scheme of authenticity as defined by the center. We begin with an analytical description of data gathered from Enshi ${ }^{1}$ to illustrate the chronotopic nature of the local production of "authentic" Tujia heritage via tourism. This takes us to an ethnographic account of China's nation-building and state politics of multiculturalism, which uncovers, in relation to this, and behind a seemingly unproblematic scene of authenticity in heritage tourism, the anxiety of inauthenticity experienced by the Tujia in Enshi with their own minority status and cultural heritage, as well as their chronotopic incorporation of both "authentic" and "inauthentic" aspects of local identity practices into a new order of authenticity from within the existing normative parameters. What emerges from such practices, we argue, is a new cultural identification, embracing not only an economic but also identity opportunity in which the orthodoxy of authenticity is becoming internalized and strategically maneuvered into the local narrative and semiotic representation of heritage and authentic self. In this sense, the Tujia in Enshi chronotopically may be shifting away from the periphery towards a new and reconfigured center of meaning-making.

1. This study is part of our ongoing ethnographic observation of Enshi as a periphery of sociolinguistic globalization, both online and offline (see e.g. Wang, 2012, 2015; Wang et al., 2014 for background and details). We take ethnography as not only a procedural methodology for extracting data through fieldwork, but also an ontological, epistemological and ethical orientation that offers in-depth, realistic and critical understandings of cultural and communication phenomena (Fabian, 1983; Hymes, 1996). The specific data on heritage tourism in Enshi presented here were collected by Xuan Wang in the summer 2013, during one of the repeated fieldwork conducted in that region. 
In what follows, we first locate our case within sociolinguistic research on heritage tourism and peripheral globalization. We then discuss the concept of chronotope and its heuristic purchase for understanding authenticity as identity practices; we consider this mainly in relation to heritage and tourism. Based on these frameworks, we empirically illustrate the chronotopic processes of semiotic production of authenticity by analyzing, first, one major heritage tourism event we encountered in Enshi, and, following this, the ethnographic history of the Tujia in Enshi in which the issue of heritage authenticity is situated, and the chronotopic reordering of authenticity by the Tujia that incorporates the logic of authenticity defined by the centers (the globalized heritage tourism and the state identity politics) into the local way of life. In the final part, we offer a critique of chronotope, authenticity and globalization in the periphery.

\section{Mapping out heritage tourism in peripheral globalization}

19 August 2013 was no ordinary day for Enshi Tujia and Miao Autonomous Prefecture, a rural minority region located in the deep mountains of Hubei Province in Central China. It was the day that marked the thirtieth anniversary of the founding of Enshi, the last officially recognized ethnic minority prefecture (of the Tujia, the Miao and twenty-six other smaller groups) in the People's Republic of China. For the local communities, this day was not only a reminder of the historic moment when an entirely different and significant political-cultural identity, of minority, was given to them by the state. It was also a formal occasion to showcase and celebrate the particular(ized) cultural heritage they have assumed since that moment, to perform and reenact that heritage in a present-day context, and to marketize aspects of authenticity in relation to their identity and heritage whether prescribed or ascribed - in order to set their foot in the new economy of heritage tourism and become part of the globalization processes in China. ${ }^{2}$ In the fortnight leading up to the special day, dozens of major events and activities were organized in various parts of Enshi (of which one will be analyzed in detail later), combining commemoration, showcasing, celebration, performing, reenactment

2. Heritage tourism became an opportunity for Enshi very recently. It emerged in the 1980s, after China's economic reform of 1979 and Enshi's recognition as an ethnic minority region in 1983. In 2000, when Enshi was absorbed into the national Great Western Development Plan, heritage tourism was adopted officially as a development strategy at the levels of the local, provincial and central government, with "strengthening the cultural foundations" and "combining minzu culture and tourism" represented by the Tujia being the top of its agenda (Wang, 2015). 
and marketization, with the Tujia, the largest indigenous ethnic group of the prefecture, playing the leading role.

What is witnessed is a remarkable instance of sociolinguistic globalization in the periphery (Wang et al., 2014; see also Heller, 2003, 2010; Blommaert, 2008, 2010; Pietikäinen \& Kelly-Holmes, 2013; Pietikäinen et al., 2016). In the periphery - being geopolitical and sociocultural minority in the case of Enshi - just as in the "center", unprecedented economic and cultural transformations as well as renewed local awareness and identity politics are to various extents taking place. For the people of Enshi, similar to disenfranchized ethnic and small-culture groups elsewhere, heritage tourism provides niched albeit crucial access to and infrastructure of globalization through which opportunities for economic and identity repositioning become available and explored. Such dynamics are sociolinguistically densely substantiated in key moments such as the founding anniversary of Enshi. What we will observe in moments like this, also as the central argument we would like to bring from this study, is that it is through multiple chronotopic organizations of semiotic and discursive maneuvering, that peripheral groups arrive at a sense of authenticity that fulfils heritage tourism as both an economic and identity project instated by globalization.

The case of Enshi focuses our gaze on specific aspects of peripherality, notably heritage, a notion intrinsic to ethnic and cultural identity and at the core of the local globalization processes, lodged in the new economy of heritage (thus identity) tourism. As suggested by Pujolar (2013: 56), "heritage is indexical of peripherality within the framework of modernity", and it is through the reproduction of the modernist ideology and discourse of antiquarianism and linguistic nationalism (as described in Bauman \& Briggs, 2003) that particular forms of the past and ways of life - i.e. history and tradition - are evoked, "invented" (Hobsbawn \& Ranger, 1983) and projected onto specific spaces and people, creating "imagined communities" (Anderson, 1991) such as the nation-state and distinct ethnocultural groups. Thus, heritage, with its particular(ized) cultural and identity forms and meanings, is a product of modernity, a self-fulfilling project in which modernity is articulated through constructing tradition as its (perceived) defining complement and contrasting Other, and "the root pair can be elaborated into a whole lexicon of dichotomous adjectives: ancient and modern, indigenous and cosmopolitan, hidden and transparent, mysterious and known, obscure and legible, pure and impure, substantial and ephemeral, and most of all authentic and inauthentic" (Upton, 2001: 298-299). In this sense, heritage encompasses multiple intersecting (e.g. geographical, economic, political, and social) dimensions of peripherality.

Perhaps it is in modern nation-building that the "ethno" layer of making heritage through the counterpart Other finds its most poignant expression. There, heritage is deployed as an instrument for the conceiving of nationhood and national 
identity, in which groups of ethnocultural minorities are created - often from the perspective of the majority groups and set off against them, representing the alterity while also being an indispensable part of a (supposedly) shared memory and history - so as to rationalize and legitimatize the hegemony of the majorities and to promote the nationalist course of unity, cohesion and homogeneity from within. The effect of such processes is not only the invention of ethnicities, what Roosens (1989) terms "ethnogenesis", but, necessarily, the minoritization and marginalization of these groups on the basis of their geography, economic power, cultural pattern, language etc., enunciated in set descriptors such as the "remote, local, agrarian, primordial, outdated, and subordinate", which are in turn circulated as historical truths.

The way in which ethnocultural heritage works as a political instrument and (controlled) knowledge basis of ethnotaxonomy for forging and maintaining nation-states and multicultural societies manifests itself in various geopolitical contexts. ${ }^{3}$ China is a case in point, wherein the state ideology and discourse of a "unified, multinational country" has resulted in the official classification of fifty-six ethnic nationalities (with the Han being the majority and constituting more than ninety percent of the Chinese population) shortly after the founding of the People's Republic in 1949 (Mullaney, 2012). This self-imagined diversity is managed through the duality of political regulation and acculturation of the "barbaric" minorities by the "advanced" Han majority (Ma, 2016), and state-sponsored multiculturalism is such that the ethnocultural identity and diversity are routinely represented in the juxtaposition of fifty-six equal but - with the exception of the Han - uniquely and exotically dressed individuals (Wang, 2015). Together, in their ethnicized and semiotized physical appearances, these individuals symbolize and embody at once the fifty-six different ethnic groups and one harmonious whole. Such an image arguably belongs to the kind of compartmentalized multiculturalism in which particular(ized) clothing (and body) becomes the essential(ized) emblematic token of ethnocultural diversity and heritage. It resonates with Gladney's (1994; see also Blum, 2001) exposition of the construction of subaltern subjects and peripheral citizens by virtue of the exoticization of the minorities in China's ethnicity politics. Hence, heritage in Chinese multiculturalism, comparable to scenes elsewhere, is a politically loaded construct that seeks out the (exotic, dissembling, visible) minority from the (normative, invisible) majority from within the nation, in order to

3. Povinelli (2002) offers a cogent example in what she terms "the cunning of recognition" in the context of Australia, where the indigenous groups have to prove their "aboriginality" based on non-indigenous knowledge, discourse and systems of recognition that serve to reinforce liberal regimes of nationalism and multiculturalism. 
sustain and authenticate its core political economy. Its logic of using cultural items, be it clothing, language, or something else, to mark out social positions and differences, closely resembles Bourdieu's (1984) notion of "distinction" thus is fraught with hegemony, inequality and peripherality.

In the context of globalization, the need for articulating and promoting heritage seems heightened. On the one hand, the deterritorialization, displacement and cultural disjunctures and differences (Appadurai, 1996) have made it all the more important to rediscover and reestablish local attachment and identity through the preservation and rejuvenation of history and heritage, both tangible and intangible. On the other hand, the emergence of heritage tourism as part of the globalized new economy has created niche markets for the production and consumption of heritage (and its associated artifacts and experiences). As demonstrated by Heller (e.g. 2003, 2010, 2014), the rise of the new economy in late capitalism rests largely on the commodification of the periphery and the transaction of the added value of symbolic distinctions between the periphery and the center, typified in the form of identity tourism. Driven by this new economic pattern, heritage tourism becomes a primary stage on which discourses, images and objects of such center-periphery distinctions - framed as heritage - are produced, performed, circulated and consumed. This form of globalization is crucial for the disenfranchized ethnic and small-culture groups, which explains the surge in heritage-based tourism activities in the ethnocultural peripheries of China.

Our discussion so far underscores the conceptualization of heritage in relation to the conditions of modernity and globalization, revealing the systemic peripherality heritage indexes and the globalized economic, political and cultural motifs in which it operates. In so doing, what we are actually problematizing, is the underlying issue of "authenticity". Given that authenticity is pivotal to both heritage as identity making and heritage as tourism commodification, we have to address the extent to which the heritage (tourism) project, such as that of Enshi, engages with the global and local regimes of meaning making and enables for itself a tenable position in both the tourism market and the cultural politics of recognition. In other words, we need to examine how the Tujia in Enshi may, through heritage tourism as a new opportunity, be considered authentic simultaneously in relation to existing state multiculturalism, the new tourist market and the place itself: authenticity as a polycentric challenge.

\section{Framing heritage authenticity and chronotopic identities}

The way authenticity is sociolinguistically materialized, indexed, negotiated and performed has been examined in the works of Coupland $(2003,2010,2014)$ and 
others (e.g. Pennycook, 2007; Blommaert \& Varis, 2013; Wilce \& Fenigsen, 2014; Lacoste, Leimgruber, \& Breyer, 2014). We take the converging arguments in these works as follows (see Coupland, 2014, for an overview): (1) authenticity is always expressed through the deployment of linguistic, discursive and/or semiotic resources; (2) in globalization, meanings of authenticity are increasingly embedded in both local and translocal frames of reference; (3) authenticity is better understood as the effect of "authentication", that is, the tensions and dynamics between normative constraints and agentive production - with the goal to establish and reach a benchmark of (often multi-layered) "enoughness"; (4) the emphasis on de-essentializing authenticity and on its performative dimension points us towards new potentials of interpreting (seemingly "inauthentic") cultural and identity behaviors.

Following on, we draw attention to the mechanisms of authenticity in heritage tourism and peripheral globalization. As said, heritage emerges as a modernist construct, with its normative parameters - "orders of authenticity" (Wang, 2012) centering on geopolitical and sociocultural peripherality and serving to sustain the political economy of the nation-state. In Chinese multiculturalism, this can be seen in the essentialized othering through exoticization of ethnocultural heritage, largely based on the state-prescribed ethnotaxonomy from the perspective of the Han majority. Heritage tourism capitalizes on exactly the kind of asymmetrical distinction created by dichotomizing the majority versus the minority, the advanced versus the barbaric, the urban versus the rural, the modern versus the traditional, the global versus the local, etc. Its core business is both the semiotization and the commodification of authenticity (Jarwoski \& Pritchard, 2005), which, on the part of the periphery-supplier, involves selecting specific cultural resources and communicating them in highly specific ways for specific audiences on specific occasions. Such processes, necessarily "inauthentic" due to modification and commodification, generate alternative revenues of "inauthentic authenticity" (Wang, 2015). As Heller (2014: 154) asserts, in understanding authenticity in the periphery, "[c]ommodification affords us a window into ongoing change, allowing us to link up individual subjectivity, interactional processes, and the conditions of the symbolic market".

How, then, can we study the actual forms taken by this sociolinguistic process of commodification, caught in the polycentric challenge of authenticity described earlier? How can we, in answering this question, also account for the inevitable "inauthenticity" connoted in the act of commodification (and associated performativity), and the way the paradoxical inauthentic authenticity is organized as a sustainable and coherent part into a shared lifeworld? Here, Bakhtin's seminal idea of "chronotope" and its recent sociolinguistic uptakes (e.g. Agha, 2007; Lampert \& Perrino, 2007; Woolard, 2013; Blommaert \& De Fina, 2017) offer a great source of inspiration. 
In Bakhtin's literary analysis, chronotope was used for addressing "the intrinsic connectedness of temporal and spatial relationships that are artistically expressed" in novels (Bakhtin 1981: 84), namely, the timespace specificity from which discourse of plot, history and identity emerges. For Bakhtin, time and space are inseparable in constructing narratives and characters; they function as a fused, concrete whole - identifiable as chronotope - which is structured and encoded in specific ways, generating historical and semiotic conditions of meaning making. This conceptualization makes it possible to dissect and describe the multiple timespace configurations that co-occur, not only in literary (en)textuality, in terms of novelistic chronotopes through which readers can extract and connect multiple social meanings and agencies represented in a story, but more generally, as cultural chronotopes: "depiction of place-time-and-personhood to which social interactants orient when they engage each other through discursive signs of any kind" (Agha, 2007: 320).

This cultural potential of chronotopes is formulated as "invokable histories" in Blommaert's (2015: 110) attempt to bring together the notion of chronotope and of context and scale for addressing the complexity of language in society. Drawing on the central argument of discourse in history, Blommaert considers chronotope as an important aspect of contextualization in which "meaning as value effects [is] derived from local enactments of historically loaded semiotic resources" (2015: 108; see also Gumperz, 2003). From this perspective, all interactive events can be seen as chronotopically organized: situated in timespace, occuring as hereand-now while indexing a myriad of "historically configured and ordered tropes" (Blommaert, 2015: 111). These tropes, or culturally recognizable systems of meanings and values, are applied and made understandable through genres, by means of ideologized, normative and enregistered features and styles that index and codify specific timespace relations. Each chronotope installs its own discursive frames and orders of indexicality (and of authenticity). Each invocation of timespace also constitutes ascription of specific genres, registers, indexicals and other chronotopically relevant norms, and, as such, enactment of specific intentions, behaviors and effects.

Building on this interpretation, chronotope can be fruitfully combined with scale, another timespace metaphor that illustrates social stratification (Blommaert, 2007, 2010; Collins et al., 2009), i.e. the ways in which language resources are unevenly distributed, and acts of communication are unequally materialized and evaluated against normative complexes and orders of indexicality, with hierarchically attributed meanings and values. Through the notion of scale, argues Blommaert (2015: 111), we are able to critically examine the chronotopic organizations of language resources in terms of "the degrees of availability and accessibility of adequate contexts creatively invoked in discourse" as well as "the scalar 
effects of recognizability". Scale points us towards "the scope of understandability [... and] scope of creativity" (ibid) of the discursive enactment of timespace, and, we may add, the interrelations of co-occurring chronotopes within that enactment (for instance, distinguished by Bakhtin as "major" and "minor") that keep different orders of authenticity in balance. The issues at stake in chronotopes, thus, are about distinctions in power, authority, agency and voice - issues that are part and parcel of the sociolinguistic critique on language and inequalities in the works of Bourdieu (1991), Hymes (1996) and others.

Blommaert's intervention on chronotope by connecting it with the notions of context and scale, is aimed at a less reductive approach to the complexity presented in "the total linguistic fact" (Silverstein, 1985), a challenge faced by sociolinguistics on how to account for

a complex construction of multiple historicities compressed into one synchronized act of performance, projecting different forms of factuality and truth, all of them ideologically configured and thus indexically deployed and all of them determined by the concrete sociolinguistic conditions of their production and uptake, endowing them with a scaled communicability at each moment of enactment

(Blommaert, 2015: 113-114)

To this end, it may well be feasible to suggest that all communicative behaviors can be examined as chronotopically organized cultural practices in which the timespace configurations reveal not only the nano politics of identity at the personal level, but also more far-reaching sociocultural changes in cultural globalization (Blommaert \& De Fina, 2017). Reflecting on this potential, we are reminded of Agha's (2007) argument for the scope of generalizability by defining chronotope as "a semiotic representation of time and space peopled by certain social types" (p. 321, our emphasis). The agentive dimension of chronotope is made translucent, as Agha (ibid) states further: "The act of producing or construing a chronotopic representation itself has a chronotopic organization (of time, space and personhood) which may be transformed by that act". The capacity to actualize recognizable meaning, personhood and social reality through chronotope points to its performative dimension - by orienting toward multiple, polycentric timespace frames and scaled normativities specified therein (Baynham, 2015). Such timespace orientations are essentially acts of identity and realizations of "recombinant selves" (Agha, 2007: 324), which in return may generate new meanings and changes, thus, pushing the boundaries of authenticity.

Relating the above understanding to our earlier discussions on heritage and authenticity, we see that the concept of chronotope has much to offer to heritage tourism and identity construction in peripheral globalization at both descriptive and analytical levels. Heritage itself is a chronotopic notion, located in 
a particular(ized) image of an eternalized past, attached to a certain place and group. The use of the term activates a whole package of associated frames and ways of thinking, talking, signing, dressing and behaving. In globalization, the chronotope of heritage, with its orders of authenticity centering on peripherality, maps onto that of the global center-periphery distinction amplified by late capitalism; while it also merges with the chronotope of tourism driven by the commodification of authenticity. All these are organized into the chronotope of locality: Enshi as a geopolitical and sociocultural periphery in China. Within this is nested yet another chronotope, that of the state multiculturalism in China emerged from its nation-building process, in which the Tujia as yet another chronotope is situated. The (multi-)chronotopic nature of our object of study is prominent and consequential. But, how are these different chronotopes semiotically combined and materialized? How might the "invokable histories" be configured into a "recombinant" new act of self? To what extent is the chronotopic organization understood as "authentic", and to whom? Let us now bring these questions into the empirical field of observation by returning to the scene, or chronotopic setting, that we have opened in the beginning.

\section{Dissecting chronotopes of authenticity}

That chronotopic setting is 19 August 2013, Enshi. The thirtieth anniversary of Enshi as the last officially recognized minority prefecture in China punctuates a crucial and sociolinguistically dense moment of identity making. It serves as a memorial of the local ethnic minority status given by the state. It opens a stage for performing and reiterating the heritage assumed by that status for the local people. It also inserts a need to promote the local heritage tourism. To put in the terms developed above, this setting is constituted into a combination of chronotopes that are called into play on a locally contrived occasion. We will now home in on the complex details and dynamics in the chronotopic configuration of the setting through a sustained look at one example.

\section{Chronotopic organization in heritage performance}

The example is one of the many events and activities organized locally in different parts of Enshi during the fortnight preceding the actual anniversary day. Our ethnographic attention, access and selection of data here are necessarily reflexively shaped by our personal and subjective encounter and experience in the field, be it sometimes "incidental" (Pinsky, 2015). In this case, this led us (through local 
acquaintances) to the small village of Shuitian Ba, on 17 August 2013, two days before the official festival date. Shuitian Ba village was, until that moment, a remote and little known hamlet in Xuan'en, the poorest county in Enshi. On that day, however, this peripheral village was turned into the center of an open air culture festival. Several heritage-related activities were taking place from dawn to dusk, including an outdoor stage performance of ethnic art, a national mountain bike tournament, and the opening of a local Tujia folk museum, attracting thousands of participants and visitors from near and far (such as Europe). A précis of the event and its multiplex timespace composition is captured in the following image (see Picture 1).

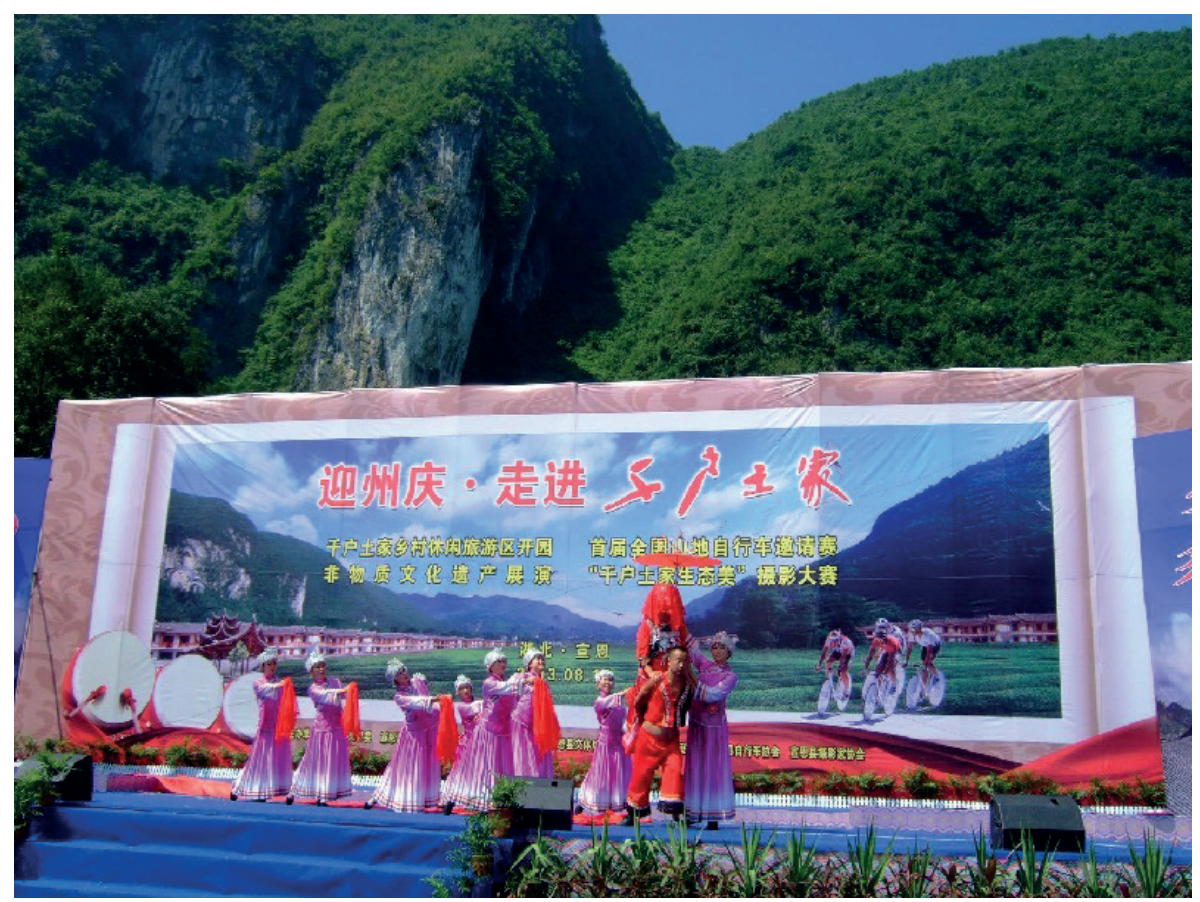

Picture 1. A chronotopic organization of "authentic" Tujia in Enshi $\odot$ Xuan Wang, 2013

What we see is part of the outdoor stage performance in the heart of the village. Two major chronotopic units are readily identifiable: one of the stage, and one of the village surroundings in which the stage is set. Each unit entails several more chronotopes that are brought in and materialized semiotically, driven by a certain ideology of heritage authenticity.

We turn first to the stage as a chronotopic unit, focusing on the semiotic framing in the stage background design. While being a chronotopic semiotization in 
itself, the stage background design also defines the overall chronotope of the event by announcing its thematic title in red characters: Prefectural Day Celebration Walk into A Thousand Tujia Households. Underneath in yellow color and smaller size, are the four sub-thematic titles: (1) A Thousand Tujia Households country leisure and tourism opening ceremony; (2) the first national mountain bike invitation tournament; (3) intangible cultural heritage show; (4) A Thousand Tujia Households Ecological Beauty photography competition. These are followed by a signature of time and space - Xuan'en, Hubei, 19 August 2013 - and completed with names of the main organizers, participant groups, and sponsors.

The core message delivered here is about Prefectural Day Celebration, the official anniversary of the local minority status received from the state. This is converted and combined into the new agenda engendered by and in turn reinforcing that status: heritage tourism, developed locally as the project of $A$ Thousand Tujia Households (more about this project below). The expression "walk into" is a public invitation, paraphrasing "welcome" and indexing a tourism marketing discourse. The centrality of this double message, of the locally implemented but statedirected political, economic and cultural priority, is indexed in the (red) color and (large) size of the writing, even in its font: with the thematic title mostly written in the font Fang Zheng (literally "clear and square"), a print font with a serious and meticulous appearance indicating formality, only leaving out the name of the local project, A Thousand Tujia Households, which adopts a calligraphy font, a more flowy handwriting style that sets the name off against the rest of the line, perhaps to imply a degree of possibility for maneuvering and creativity.

Several sub chronotopes can be also observed, pointing to distinct yet interrelated elements of the heritage tourism project implemented in Shuitian Ba and opening for interpretation and consumption on the day. These elements correspond with the sub-thematic titles mentioned above, and chronotopically reorganize the place as a destination (1) of rural tourism, represented in its ethnicized primordial, idyllic lifestyle; (2) of extreme tourism, explorable as a remote and dangerous place through the modern adventure sport of mountain biking; (3) of cultural tourism, inhabited by the ethnic Other, crystallized and exhibited in certain (intangible) forms of tradition; and (4) of ecotourism, as a space undisturbed by modern living, with uncontaminated natural beauty. Taken together, these strands index and put into practice the logic of heritage tourism and its tropes (multilayered and revolving around peripherality), co-constructing an "authentic" local through the commodification of its profound peripherality.

The intertwining of these chronotopes sanctions and "orders" the deployment of more semiotic indexicals into that same stage background design, in the form of a collage of different images on which all the aforementioned thematic titles are inscribed. In this collage, Shuitian Ba village is seen lying peacefully in the gentle 
cradle of beautiful mountains (which until recently were iconic of Enshi's remoteness and poverty). The center of the panoramic view is occupied by a stretch of lushly green tea fields (tea has been a well-known produce of Xuan'en for two centuries). On both sides of the fields, along the foot of the mountains, sit small, tidy clusters of "traditional" farm houses (which were in fact newly built under the local A Thousand Tujia Households project). In the bottom right corner of the collage, we also find a superimposed image of professional-looking road cyclists in action (an image associated with modern sports originated from Western Europe). Undoubtedly, these images are carefully selected and chronotopically reorganized into the stage background design. The aesthetic depiction of the village echoes and complements the (rural, adventure, cultural, and eco-) forms of heritage tourism inscribed in the thematic titles listed above. They also reaffirm ideologically the local multiple orientations to the translocal (heritage) authenticity simultaneously invoked in these titles - we are observing what Blommaert (2005: 126) called "layered simultaneity" here. Shuitian Ba village is authentic, as it seems, because of the confluence of all of these elements in that historical-synchronic moment of enactment and observation. The chronotopically invoked words, images and ideas of heritage-as-tourism, as evidenced so far, all point to authenticity as a romanticized, exoticized and commodified version of peripherality. This version of peripherality, as we will see next, is embedded in and mobilized in support of the overall heritage project of Enshi: the construction of an authentic minority identity of the Tujia.

Let us now look at the second aspect of the stage, the actual show unfolding within that chronotope. What is being performed is a dramatized dance called Ten Sisters, which reenacts the Tujia tradition of "wedding lament". This performance is yet another chronotopic organization, richly semiotized through music, singing, costumes, body movements and storytelling. We see that all dancers are dressed in supposedly Tujia-style costumes (the "authentic" Tujia costumes are hard to identify, see Wang, 2015). The bride and the groom are wearing matching red. With head covered under a red veil, the bride is being carried away by the groom on his back. The bridesmaids, the other nine of the ten sisters, are in identical pink dresses. They line up behind the couple, crying and waving farewell to the bride with red handkerchiefs. One of them seems to find it difficult to see off the bride: she stands by the couple, holding a red umbrella over the bride to shelter her from the sun. The music is sad and grieving, and the lyrics speak about the bride's reluctance to leave home and her gratitude to her parents.

The "invokable histories" of this chronotopic organization, taking the form of dance show, are indexical of China's state ideology of multiculturalism and its imperative perception and representation of ethnic minorities. As discussed earlier, this ideology derives from an ethnotaxonomy, claiming certain (sometimes imagined or caricatured) aspects of the past or distinctions as traditions and 
ethnically "unique" heritage, and circulating these as knowledge and truth that transcend timespace. This order of authenticity overarches the heritage making in Enshi. Although the wedding lament is a dated custom once practiced in many Han and other ethnic communities in China (and elsewhere), it has been officially attached to the Tujia and assumed as part of the group's timeless, unique feature and cultural heritage. The ritual is reenacted and chronotopically incorporated into various identity moments to indicate authenticity, such as here on the stage in Shuitian Ba village for the thirtieth anniversary of Enshi. In fact, wedding lament has become a Tujia "classic"; the ritual - or, rather, the idea of it - has been enregistered as part of the local identity repertoire even though the vast majority in Enshi have not even seen it in its "authentic" form themselves.

The dance performance of Ten Sisters in Shuitian Ba is one of the numerous reinterpretations of the Tujia wedding lament ritual. Within its own timespace frame as a dance, it artistically and intertextually recycles the official discourse of the "authentic" Tujia. Meanwhile, the dance serves as a focal point of the chronotope generated on the stage: it ties in with the theme "intangible cultural heritage show" written in the stage background design; it delivers that theme through selected multimodal semiosis and, via the stage, opens its semiotization of authenticity to multiple audiences and interpretations. The dancers on this stage are what we might call the "heritagized" body. By being members of the local communities, wearing the Tujia-style clothing, and doing the ritual of wedding lament through dancing, the dancers themselves have become the most "authentic" embodiment of Tujia authenticity. The bodies per se and what they can do and represent, in this sense, are called upon as an elemental form of chronotopic resource for achieving that authenticity, thus, an elemental part of the Tujia heritage. This insertion of the "heritagized" body onto the stage is the semiotic axis to all the chronotopic work, i.e. heritage-as-ethnicity, unfolding in that moment of celebration in Shuitian Ba.

This brings us to the village as a chronotopic unit in which the celebration event takes place. We see the mountains iconic of Shuitian Ba being a central part of this chronotope. They frame the stage celebration as both the natural landscape of the village and the stage background design. This creates an authenticating effect to what is happening on the stage and, by extension, to the Tujia heritage projected from that stage. The same can be said about the corporeal and semiotic juxtaposition of the tea fields, the traditional farm houses and the cyclists. The village provides the locality and a foundational timespace framework. However, locality is not merely the backdrop outside of things that are happening, it is also designed and brought in as a key chronotopic resource.

A Thousand Tujia Households is a local heritage project that has turned Shuitian Ba village into the ideal(ized) locality for the celebration. The project, funded by the county government of Xuan'en, was to make a model village out of Shuitian 
Ba showcasing the natural beauty of the mountainous region, the idyllic agrarian lifestyle, and the unique Tujia way of life, focusing on housing - all in all, an "authentic" package of heritage features under the umbrella term of Tujia, which feeds directly into the heritage tourism market and its commodification of Tujia authenticity. We have seen all of these semiotically represented on the stage. Not as immediately visible in that synchronicity, is the process of (chronotopic) design of the village. To achieve the goal, the village has been transformed. The previous paddy fields (origin of the village name) were replaced with tea fields, concentrated in the primary location of village centre. New roads and paths were built, featuring a Dong ${ }^{4}$-style footbridge over the brook running through the village. The location and size of the local farm houses were also reorganized so that they would look tidier and more uniformly recognizable. More interestingly, a proportion of the project funding was spent on revamping these houses to give them an ethnically "authentic" appearance. This involved replastering the external walls of many houses to hide their originally tiled facades (the latter was an urban trend in Enshi at the time), replacing the aluminium window frames with carved wooden ones, and adding artistic features to the roofs and eaves of the houses. All these efforts have contributed to the "authentic" locality and are visually connected to other "authentic" products and performances found in the village.

One may ask whether the production of locality here have paradoxically triggered "artificial authenticity", therefore, inauthenticity. However, what counts as the original? Is the original the authentic? At what point does an intentional adjustment turn its object into something inauthentic? Answers to such questions are contentious and complex. We prefer to consider the A Thousand Tujia Households project as an example in which the semiotic modification of a chronotopic setting is part of the wider process of striving for a sense of authenticity at different scale-levels; it therefore belongs to the production of authenticity.

To summarize, the example from Shuitian Ba village illustrates complex chronotopic organizations of different aspects of the Tujia heritage in action. In the format of a stage performance, different timespace frames are mobilized to represent the "authentic" Tujia for political and economic purposes. The stage and the village become multi-chronotopic, in the sense that they generate a nexus of chronotopes, with the Tujia dance performance being the focal point, and the stage background design semiotically mirroring the corporeal surroundings and activities of the occasion. Each chronotope brings along its own historical meanings, with different configurations and meanings merging into a fused whole through the stage setting on which the Tujia heritage is performed - in a double sense of

4. Another ethnic minority group found in Enshi. 
the word: as a theatrical performance, and as an agentive process of semiotization. This performative aspect, as we have seen, involves notable efforts of "semiotic design" (Wang, 2015). Chronotopes examined here are necessarily part of the larger chronotopes of heritage in Enshi, in China and in globalization. They show that the performance of heritage authenticity, or any identity claim, is organized in relation to multiple timespace frames of meaning making.

\section{Chronotopic scaling and authenticity}

We have suggested earlier that scale is a notion that can describe the scope of communicability of chronotopically organized and semiotized behaviours (Blommaert, 2015). If heritage can be observed as such a phenomenon, following our discussion so far, tourism offers a scale at which heritage can be articulated, negotiated and understood. The scale of tourism mobilizes specific norms, genres and expectations toward which communication on heritage and authenticity orients - we have seen these in the case of Enshi being "translated" into the globalized formats of rural, adventure, ethnic, and eco- tourism and respective spatiotemporal configuration of local engagements. There are other scales that are prevalent, such as the state ethnopolitics of multiculturalism, or the local histories and conditions. All these scales inform and shape the way heritage can be performed and developed in an "authentic" way. This suggests that heritage is a profoundly multiscalar and polycentric process, in which different scales interact with one another, but not on equal footings. They may come into play at a semiotic, ideological or discursive level. They may work in parallel, conjoint, competing or conflicting relations with one another, and in turn involve different contributors and evaluators. The outcome is heteroglossic, a package of multiple meanings and voices. Thus, such dynamics and the opportunities, tensions and transactions they instigate qualify "heritage" as a verb (to echo Street, 1993).

From this perspective, heritage can be understood as a scaled collective process of meaning making in a given timespace. "Heritaging", we might say, is a matter of scaling: maneuvering with the dialectic interplays of the relevant scales to arrive at a sense of authenticity through chronotopically organized "synchronized" activities. This understanding may go some way to explaining our remaining questions on the issue of heritage authenticity we have encountered in Enshi, an issue that appears to be largely about responding to the orders of authenticity at the scale of globalized heritage tourism and that of state heritage politics. Through the example illustrated above, we have gained insight into the intricate chronotopic organizations of heritage authenticity, and understood that it is within a complex regime of normativities that a range of chronotopes are brought together 
to explore an important identity opportunity for Enshi. The questions we are left with are: in what way can we actually interpret the local uptake of heritage tourism under these conditions still as an agentive process of heritaging and, in the end, self-realized authenticity for the community itself? In what way can we keep a balanced view between the conformative and the performative, the staged and the everyday, the authentic and the inauthentic, in order to better account for meaning making in the periphery? To answer these questions we have to start somewhere else, with the genesis of Enshi Tujia and Miao Autonomous Prefecture.

The establishment of Enshi's minority status through its ethnic population of the Tujia was a convoluted story. In the process of nation building after 1949, the Chinese government implemented ethnic classification in order to give recognition to minority groups and to integrate them into a "unified, multinational country". A large number of the fifty-five minority groups we now know in China were officially identified in the 1950s. Each ethnic group, called minzu, (supposedly) has its own territory, common history, unique language, culture and tradition. However, as Mullaney (2011) shows in his account of this part of Chinese history, the ethnotaxonomy applied at the time had its epistemological, ontological and methodological foundations in Western modernist social scientific beliefs in disciplines such as linguistics and ethnology (and, we could add, its political conversion into a "model state", the Soviet Union). It was unable to clearly define all ethnic groups according to pre-assumed, fixed categories such as language or specific cultural traits. The Tujia group was not recognized until 1957 because the group had been mixing and living together with other groups; they lacked the obvious cultural features that would make them visibly different from the other groups. Its classification was prompted accidentally when a representative of the Miao from a town bordering Hunan and Hubei provinces pleaded with the central government to "reclassify" her and her people in Hunan as the Tujia, since their language differed from that of the Miao (Tan \& Hu, 2009).

However, whereas areas in Western Hunan were officially recognized in 1957 as Tujia territories, based on the local communities' self identification and fieldwork conducted by Chinese ethnologists, their neighbours in Enshi, Western Hubei, did not receive the same recognition. The ethnic classification was soon brought to a halt with the change of political climate in China prefiguring the Great Proletarian Cultural Revolution, when claiming any different identity risked being seen as counter-revolutionary factionism. It was not until after the Cultural Revolution that the ethnic classification was resumed, to address some of the issues left over from two decades ago. Enshi's case reopened.

Brown (2002) records that when the status reclassification and restoration of the Tujia started in Enshi in early 1980s, many local people were unwilling to "become" Tujia since they "did not have Tujia consciousness" (ibid: 375 ) and preferred to con- 
sider themselves Han. Brown argues that the categories of ethnic boundary and distinction created by the local government - mainly by genealogical information and history of residence - did not reflect the actual cultural practice and sociopolitical experience of the individuals; it was a "manipulation" of population statistics based on an artificial dichotomy between the Tujia and the Han, a tactic of authentication by the local government that was "both economically beneficial and politically safe" for the local populace as a whole (ibid: 389). The disjunction between the state recognition and the local sense of self observed here illustrates the sensitivity and power dynamics of authenticity in relation to ethnic identity in China - particularly so for Enshi - in which the influence of the state prevails.

In the light of this historical trajectory, we may understand that for Enshi, what heritaging initially invokes is perhaps an uncomfortable sense of inauthenticity rather than authenticity and, consequently, anxiety about how to become authentic. This question is hardly meaningful in terms of daily life at the local scale, since being a minority, whether as a Tujia, a Miao, or a member of another minority group, or even being a majority, in the reality of Enshi, was only an abstract political status largely detached from local personal realities: nearly all the features and evidence of "authenticity", such as ethnic language, clothing and customs, are absent, including people's own ethnic consciousness. The question until recently has only been relevant and important at the national scale: how to be seen as authentic in the eyes of the state, of the majorities and of the other minorities. The chronotopes of the local group identity were separated and confined in two disjointed scales of meaning making in terms of heritage. When called upon by the state as minority, people shift into a "heritage" mode or chronotope of communication, deploying "authentic" heritage-related semiotic resources. The moment this duty is done, they shift out of it, picking up a different, "inauthentic" set of resources to continue with life at the local level. The contrast and disjunction and the essentializing accusation of inauthenticity these often produce only accentuate the peripheral status of Enshi.

This predicament, however, is now brought in a different light, with globalization and heritage tourism opening up new economic, political and cultural opportunities for Enshi. Tourism began to take shape in Enshi in the late 1980s, after its reintegration and recognition as a minority region, but only came into full swing less than a decade ago. The old question of "how to play the minzu [ethnic minority] card" began to merge with the new economic demand, leading to the local strategizing of heritage tourism, with the Tujia (now the largest minority group of Enshi) being positioned as its spearhead. The entrée of a new heritage discourse from the global scale begins to reshape the meaning of authenticity in Enshi. Its natural scenery of steep mountains and local culture have been politically reframed and economically repackaged, turning from an image of wilderness and underdevelopment into one of rare beauty, ecological privilege, nostalgic 
leisure and bucolic life. This indicates a symbolic shift in the order of authenticity that has historically stigmatized Enshi.

The global template of heritage tourism simultaneously authenticates and de-authenticates heritage. On the one hand, it seeks the "real" local in order to commodify it; on the other hand, it disrupts and "contaminates" the local way of life through translocal encounters and involvements - tourists are by definition not local, "not from here". This creates scaled chronotopic patterns that reorganize heritage into the (authentic) "timeless-here" in mixture and coordination with the (inauthentic) commodification and rescrambling of timespace and resources, as we have seen in the example of Shuitian Ba in Enshi. There, it seems, the new order of authenticity at the global scale-level offers scope and chronotopic opportunities to simultaneously articulate heritage authenticity at the national and the local scale-levels: people can fit their previously disjointed "on" and "off" modes of heritage within the one chronotope of heritage tourism. By moving up and mixing scales, they manage to obtain a degree of coherence and sustainability in their dilemma of inauthentic authenticity - heritage is now chronotopically niched.

More important to our understanding about Enshi is the emerging agency involved in this reorganization. The absorption into globalization processes through heritage tourism is subtly transforming the identity making processes for Enshi. The opportunities put forward to the local communities have enabled them to engage with their "given" heritage and the question of "how to become authentic" in a more autonomously active way. This is evidenced in Enshi's full orientation toward tourism as a heritage strategy and the political and economic investments it makes accordingly. It is also evidenced in the local commitment to identity opportunities like the one we discussed, through the detailed, layered semiotic maneuvers so as to better perform Tujia authenticity; and it is evidenced in the scaling of heritage practices accumulated from such opportunities toward authenticity of optimal potential of recognizability. The efforts are about appropriating these opportunities, as much as about developing an order of authenticity that is locally enacted and translocally meaningful, both stimulate and rely on active semiotic design. It is in these facts that we begin to see an inception of ethnic consciousness in Enshi. In this sense, what we are also witnessing is a contemporary process of ethnogenesis, that is, the invention of the Tujia and their heritage.

\section{Conclusion}

Meaning making in the global periphery is infused with complexity. To adequately address that complexity is one of the main challenges we are faced with in sociolinguistic studies. Through the case of the Tujia in Enshi, it is clear that any critical 
understanding about the complexity cannot disengage with the structural conditions of peripherality and inequality in which accessibility, communicability and validity of language resources and their use are embedded. For ethnic minorities such as the Tujia, heritage is a compelling identity discourse with historically loaded and regimented meanings and values. It came with the minority status that was "given" by the state to people in Enshi, marking out their (invented) cultural alterity and geopolitical peripherality. Therefore, what their "own" heritage invokes is not only an unfamiliar (sometimes absent) set of semiotic norms and resources, but also the perpetual ambivalence of (in)authenticity.

This ambivalence reemerges through heritage tourism as the Tujia engage in processes of globalization. Heritage tourism opens for Enshi an opportunity to commodify their peripherality - which has now become a resource - while addressing the issue of authenticity. By incorporating the notion of chronotope, we are able to ethnographically contextualize and dissect the local identity acts demanded by heritage tourism, but performed simultaneously at multiple scalelevels. It transpires that these acts entail careful semiotization of timespace in which authenticity is communicated in a spatially and temporally reorganized, rerationalized order. In this new order of authenticity, the Tujia are able to design and deliver what may be considered authentic for different audiences while gaining economic and political purchase. They are heritaging in ways that, previously were mainly meaningful to others, but now are also meaningful for themselves. In this sense, they are becoming Tujia, and their heritaging is "producing authenticity" (Cavanaugh \& Shankar, 2014).

Furthermore, heritage in a globalizing era is better understood as something chronotopically niched. The assumption of heritage as a singular chronotope of "timeless-here" (in crystallized forms of language, clothing and other cultural traits) can no longer sufficiently explain what counts as authentic or inauthentic (see also Woolard, 2013). The binary view is under challenge in an increasingly polycentric environment in which heritaging now operates. The authenticity claims it can make are not simply against the essentialized norm imposed from one centre, but through a complex process that involves semiotic maneuvering targeting recognizability for multiple centers and scales. Through chronotopic maneuvering, "fake" acts (which are often produced for those who consider them as such), such as stage performing, designing and commodification, are able to find their own place and validity in heritaging, making themselves a coherent and sustainable part of a co-constructed lifeworld. In this way, heritage is renewed, revised and reinserted in contemporary life - as part of the ongoing "invention of tradition" in human society (Hobsbawn \& Ranger, 1983).

This, to some extent, makes authenticity a politically more viable course for those in the periphery. As shown in the case of the Tujia, through their agency, 
peripheral groups are able to - even if symbolically - reclaim authenticity over certain ground, thus, a degree of autonomy over their own identity making. In minute semiotic details of performing heritage, we detect that the center-periphery relation is being locally contested and reworked, from which cultural change is emerging. However, we must also avoid the over-generalization that those in the periphery are free from the structural inequality that circumscribes their authenticity. As our study suggests, the production of a new order of authenticity is still largely situated in a peripheral cultural and political economy, based on patterns and resources defined by the center. Its own authenticity, therefore, has not escaped "the cunning of recognition" (Povinelli, 2002) within globalization.

\section{Acknowledgements}

We wish to thank our editors for their time and patience, and the anonymous reviewers for their valuable comments and suggestions for improving an earlier draft of this paper. We also thank Jan Blommaert and other colleagues at Babylon Centre for the Study of Superdiversity, Tilburg University, for ongoing illuminating conversations about not only ideas relevant to this paper, but also a wide range of issues on language, culture and globalization. In the process of developing this paper, we have benefited greatly from the insightful works presented to the panel Chronotopic Identity Work at Sociolinguistic Symposium 21 (University of Murcia, 2016). Last but not the least, our gratitude goes specially to Long Jianghua, Wang Mian, Xie Hongyan, Zhang Ting and Zhang Xiuju in Enshi, who generously provided crucial inside knowledge and logistic assistance without which the fieldwork that has inspired this paper would have simply been impossible.

\section{References}

Agha, A. (2007). Recombinant selves in mass mediated spacetime. Language \& Communication, 27, 320-335. doi:10.1016/j.langcom.2007.01.001

Anderson, B. (1991). Imagined Communities: Reflections on the origin and spread of nationalism. London: Verso.

Appadurai, A. (1996). Modernity at large: Cultural dimensions of globalization. Minneapolis, MN: University of Minnesota Press.

Bakhtin, M. M. (1981). Forms of time and of the chronotope in the novel. In M. Holquist (Ed.), The dialogic imagination (pp. 84-258). Austin, TX: University of Texas Press.

Bauman, R., \& Briggs, C. (2003). Voices of modernity: Language ideologies and the politics of inequality. Cambridge: Cambridge University Press. doi:10.1017/CBO9780511486647

Baynham, M. (2015). Narrative and space/time. In A. De Fina \& A. Georgakopoulou (Eds.), The handbook of narrative analysis (pp. 119-139). Chichester: John Wiley \& Sons.

Blommaert, J. (2005). Discourse. Cambridge: Cambridge University Press. doi: $10.1017 / C B O 9780511610295$ 
Blommaert, J. (2007). Sociolinguistic scales. Intercultural Pragmatics, 4(1), 1-19. doi:10.1515/IP.2007.001

Blommaert, J. (2008). Grassroots literacy: Writing, identity and voice in South Africa. London: Routledge.

Blommaert, J. (2010). The sociolinguistics of globalization. Cambridge: Cambridge University Press. doi:10.1017/CBO9780511845307

Blommaert, J. (2015). Chronotopes, scales, and complexity in the study of language in society. Annual Review of Anthropology, 44, 105-116. doi:10.1146/annurev-anthro-102214-014035

Blommaert, J., and Varis, P. (2013). Enough is enough: The heuristics of authenticity in superdiversity. In J. Duarte \& I. Gogolin (Eds.), Linguistic superdiversity in urban areas: Research approaches (pp. 143-159). Amsterdam: John Benjamins. doi:10.1075/hsld.2.10blo

Blommaert, J., \& De Fina, A. (2017). Chronotopic identities: On the timespace organization of who we are. In A. De Fina, J. Wenger, \& D. Ikizoglu. (Eds.), Diversity and super-diversity: Sociolcultural linguistics perspectives (pp. 1-15). Washington, DC: Georgetown University Press.

Blum, S. D. (2001). Portraits of primitives: Ordering human kinds in the Chinese nation. Lanham, MD: Rowman \& Littlefield.

Bourdieu, P. (1984). Distinction: A social critique of the judgement of taste. London: Routledge.

Bourdieu, P. (1991). Language and symbolic power. Cambridge, MA: Harvard University Press.

Brown, M. (2002). Local government agency: Manipulating Tujia identity. Modern China, 28(3), 362-395. doi:10.1177/00900402028003003

Cavanaugh, J. R., \& Shankar, S. (2014). Producing authenticity in global capitalism: Language, materiality, and value. American Anthropologist, 116(1), 51-64. doi:10.1111/aman.12075

Ch'en, J. (1992). The highlanders of central China: A history, 1893-1937. Armonk: M. E. Sharpe.

Collins, J., Slembrouck, J., \& Baynham, M. (Eds.). (2009). Globalization and languages in contact: Scale, migration, and communicative practices. London: Continuum.

Coupland, N. (2003). Sociolinguistic authenticities. Journal of Sociolinguistics, 7(3), 417-431. doi:10.1111/1467-9481.00233

Coupland, N. (2010). The authentic speaker and the speech community. In C. Llamas \& D. Watts (Eds.), Language and identities (pp.99-112). Edinburgh: Edinburgh University Press.

Coupland, N. (2014). Language, society and authenticity: Themes and perspectives. In V. Lacoste, J. Leimgruber, \& T. Breyer (Eds.), Indexing authenticity: Sociolinguistic perspectives (pp. 14-42). Berlin: Walter de Gruyter.

Fabian, J. (1983). Time and the other: How anthropology makes its object. New York, NY: Columbia University Press.

Gladney, D. (1994). Representing nationality in China: Refiguring majority/minority identities. Journal of Asian Studies, 53(1), 92-123. doi:10.2307/2059528

Gumperz, J. (2003). Response essay. In S. L. Eerdmans, C. L. Previgniano, \& P. J. Thibault (Eds.), Language and interaction: Discussion with John J. Gumperz (pp. 105-126). Amsterdam: John Benjamins. doi:10.1075/z.117.09gum

Heller, M. (2003). Globalization, the new economy, and the commodification of language and identity. Journal of Sociolinguistics, 7, 473-498. doi:10.1111/j.1467-9841.2003.00238.x

Heller, M. (2010). Language as resource in the globalized new economy. In N. Coupland (Ed.), The handbook of language and globalization (pp. 349-365). Chichester: Wiley-Blackwell. doi:10.1002/9781444324068.ch15 
Heller, M. (2014). The commodification of authenticity. In V. Lacoste, J. Leimgruber, and T. Breyer (Eds.), Indexing authenticity: Sociolinguistic perspectives (pp. 112-136). Berlin: Walter de Gruyter.

Hobsbawn, E., \& Ranger, T. (Eds.). (1983). The invention of tradition. Cambridge: Cambridge University Press.

Hymes, D. (1996). Ethnography, linguistics, narrative inequality: Toward an understanding of voice. London: Taylor and Francis.

Jaworski, A., \& Pritchard, A. (Eds.). (2005). Discourse, communication and tourism. Bristol: Channel View Publications.

Lacoste, V., Leimgruber, J., \& Breyer, T. (Eds.). (2014). Indexing authenticity: Sociolinguistic perspectives. Berlin: Walter de Gruyter.

Lampert, M., \& Perrino, S. (Eds.). (2007). Entextualization and temperality. Special issue of Language \& Communication, 27, 205-335.

Ma, R. (2016). "Culturalism" and "Nationalism" in Modern China. In M. Guibernau \& J. Rex (Eds.), The Ethnic Reader: Nationalism, multiculturalism and migration (pp. 299-307). Cambridge: Polity Press.

Mullaney, T. S. (2012). Coming to terms with the nation: Ethnic classification in modern China. Berkeley, CA: University of California Press.

Pennycook, A. (2007). Language, localization, and the real: Hip-hop and the global spread of authenticity. Journal of Language, Identity and Education, 6(2), 101-115. doi:10.1080/15348450701341246

Pietikäinen, S., \& Kelly-Holmes, H. (Eds.). (2013). Multilingualism and the periphery. Oxford: OUP. doi:10.1093/acprof:0so/9780199945177.001.0001

Pietikäinen, S., Kelly-Holmes, H., Jaffe, A., \& Coupland, N. (2016). Sociolinguistics from the periphery: Small languages in new circumstances. Cambridge: Cambridge University Press.

Pinksy, D. (2015). The sustained snapshot: Incidental ethnographic encounters in qualitative interview studies. Qualitative Research, 15(3), 281-295. doi:10.1177/1468794112473493

Pujolar, J. (2013). Tourism and gender in linguistic minority communities. In S. Pietikäinen \& H. Kelly-Holmes (Eds.), Multilingualism and the periphery (pp. 55-76). Oxford: Oxford University Press. doi:10.1093/acprof:0so/9780199945177.003.0004

Povinelli, E. A. (2002). The cunning of recognition: Indigenous alterities and the making of Australia multiculturalism. Durham, NC: Duke University Press. doi: $10.1215 / 9780822383673$

Roosens, E. (1989). Creating ethnicity: The process of ethnogenesis. London: Sage.

Silverstein, M. (1985). Language and the culture of gender. In E. Mertz \& R. Parmentier (Eds.), Semiotic Mediation (pp. 219-259). New York, NY: Academic Press. doi:10.1016/B978-0-12-491280-9.50016-9

Street, B. (1993). Culture is a verb: Anthropological aspects of language and cultural process. In D. Graddol, L. Thompson, \& M. Byram (Eds.), Language and culture (pp. 23-43). Clevedon: British Association of Applied Linguistics.

Tan, H. Z., \& Hu, X. H. (2009). The Tujia daughter Tian Xin Tao (土家女儿田心桃). Beijing: Publishing House of Minority Nationalities.

Upton, D. (2001). “Authentic" anxieties. In N. Alsayyad (Ed.), Consuming tradition, manufacturing heritage: Global norms and urban forms in the age of tourism (pp. 298-306). London: Routledge.

Wang, X. (2012). "I am not a qualified dialect rapper": Constructing Hip-Hop authenticity in China. Sociolinguistic Studies, 6(2), 153-191. 
Wang, X. (2015). Inauthentic authenticity: Semiotic design and globalization in the margins of China. Semiotica, 203. 227-248.

Wang, X., Spotti, M., Juffermans, M., Cornips, L., Kroon, S., \& Blommaert, J. (2014). Globalization in the margins: Toward a re-evaluation of language and mobility. Applied Linguistics Review, 5(1), 23-44. doi:10.1515/applirev-2014-0002

Wilce, J., \& Fenigsen, J. (Eds.). (2014). De-essentializing authenticity: A semiotic approach. Special issue of Semiotica, 203, 137-248.

Woolard, K. (2013). Is the personal political? Chronotopes and changing stances toward Catalan language and identity. International Journal of Bilingual Education and Bilingualism, 16(2), 210-224. doi:10.1080/13670050.2012.720670 